\title{
Pencegahan Anemia Santri Putri Melalui Perbandingan Konsumsi Suplementasi Tablet Tambah Darah Dengan Kapsul Serbuk Moringa Oleifera Leaf
}

\section{Prevention Of Anemia in Female Santri Through Comparison Of Blood Added Tablet Supplementation With Powder Capsule Moringa Oleifera Leaf}

\author{
Azizatul Hamidiyah ${ }^{1}$, Lutfiatur Rohmani ${ }^{2}$ \\ 1,2Program Studi Kebidanan, Fakultas Ilmu Kesehatan, Universitas Ibrahimy \\ 1Email: azizatulhamidivah@gmail.com
}

\begin{abstract}
ABSTRAK
Anemia merupakan masalah kesehatan yang banyak terjadi terutama di negara berkembang. Anemia pada remaja putri dapat menyebabkan risiko gangguan fisik dan mental, meningkatkan risiko $\mathrm{t}$ gangguan saat periode kehamilan nantinya. Salah satu upaya yang dapat dilakukan dalam penanggulangan anemia adalah dengan suplementasi zat besi. Akan tetapi program ini belum berjalan maksimal dan supmenen tablet tambah darah yang diberikan perlu dievaluasi ulang mengingat merupakan produk kimia yang tentu kurang baik jika dikonsumsi secara rutin bagi ginjal. Sehingga perlu dilakukan pengembangan produk yang lebih aman untuk dikonsumsi secara rutin. Tujuan penelitian ini yaitu untuk mengetahui perbandingan konsumsi suplementasi tablet tambah darah dan kapsul serbuk Moringa Oleifera Leaf dalam pencegahan anemia remaja putri di Pondok Pesantren Salafiyah Syafiiyah Sukorejo. Penelitian ini merupakan penelitian kuantitatif dengan desain True Eksperimen. Waktu penelitian dilakukan selama 10 bulan pada Tahun 2020. Sampel dalam penelitian ini terdiri dari masing-masing 30 remaja putri baik kelompok intervensi maupun control. Instrumen dalam penelitian ini yaitu 1) lembar observasi hasil pengamatan Kadar Hemoglobin, 3) Lembar observasi recall gizi dan lama waktu tidur untuk mengontrol bias, 4) Set alat Hemoglobin Test merk Quick Check, darah responden, alcohol swab, blood lancet. Analisis data dilakukan menggunakan uji univariat dan bivariat (Wilcoxon). Hasil penelitian menunjukkan ada perbedaan konsumsi suplementasi tablet tambah darah dan kapsul serbuk Moringa Oleifera Leaf dalam pencegahan anemia remaja putri di Pondok Pesantren Salafiyah Syafiiyah Sukorejo (Pvalue 0,047).
\end{abstract}

Kata kunci: Anemia, Suplementasi Tablet Tambah Darah, Kapsul Serbuk Moringa Oleifera Leaf

\begin{abstract}
Anemia is a common health problem, especially in developing countries. Anemia in adolescent girls is a risk of physical and mental dysfunction, and can increase the risk of interference during pregnancy later. One of the efforts that can be done in overcoming anemia is iron supplementation. However, this program has not run optimally and the supplemental blood supplement tablet given needs to be re-evaluated considering that it is a chemical product which is certainly not good if consumed regularly for the kidneys. So it is necessary to develop products that are safer for regular consumption. The purpose of this study was to determine the comparison of the consumption of supplementation with blood-added tablets and capsules of Moringa Oleifera Leaf powder in the prevention of anemia in adolescent girls at Pondok Pesantren Salafiyah Syafiiyah Sukorejo. This research was a quantitative study with a True Experiment design. The research was conducted for 10 months in 2020. The sample in this study consisted of 30 girls each, both in the intervention and control groups. The instruments in this study were 1) observation sheet of observation result of hemoglobin level, 3) observation sheet of nutrition recall and length of sleep to control bias, 4) Set of Quick Check brand Hemoglobin Test, respondent's blood, alcohol swab, blood lancet. Data analysis was performed using univariate and bivariate (Wilcoxon) tests. The results showed that there were differences in the consumption of supplementation with blood-added tablets and capsules of Moringa Oleifera Leaf powder in the prevention of anemia in adolescent girls at Salafiyah Syafiiyah Sukorejo boarding school (Pvalue 0.047).
\end{abstract}

Keywords: Anemia, Blood Added Tablet Supplementation, Powder Capsule Moringan Oleifera Leaf 


\section{PENDAHULUAN}

Anemia merupakan masalah kesehatan yang banyak terjadi terutama di negara berkembang. Remaja putri berisiko menderita anemia sepuluh kali dibandingkan dengan remaja putra. Remaja putri membutuhkan besih lebih banyak karena percepatan growth spurt dan menstruasi (Lych, 2000). Anemia remaja dapat menyebabkan keterlambatan pertumbuhan fisik, gangguan perilaku dan emosional. Bila keadaan akut, anemia dapat menyebabkan kematian. Anemia remaja putri juga berisiko meningkatkan risiko terjadinya gangguan kehamilan nantinya (Sediaoetomo, 1992). Menurut Yip (1998) kebutuhan zat besi perlu diperbaiki sejak remaja sehingga anemia pada saat kehamilan dapat dicegah.

Menurut WHO (2013), prevalensi anemia dunia berkisar 40$88 \%$. Berdasarkan data hasil Riskesdas tahun 2013, prevalensi anemia di Indonesia yaitu $21,7 \%$ penderita anemia berumur 15-24 tahun sebesar 18,4\% (Kemenkes RI, 2013). Survey yang dilakukan kepada siswa sekolah di Indonesia menunjukkan prevalensi anemia sebesar 36\%-43\% (Astuti \& Rosidi, 2011).
Hasil penelitian yang dilakukan oleh Hamidiyah (2018) menunjukkan bahwa 111 dari 140 (79\%) santri putri asrama pusat Pondok Pesantren Salafiyah Syafi'iyah Sukorejo mengalami anemia. Begitu pula berdasarkan hasil penelitian yang dilakukan oleh Soan (2018) menunjukkan bahwa 87 dari 90 (97\%) mahasiswa Kebidanan Universitas Ibrahimy mengalami anemia.

Secara umum tingginya prevalensi anemia di Indonesia disebabkan defisiensi besi dan mineral lainnya, seperti vitamin $\mathrm{A}, \mathrm{C}$, folat, riboplafin dan B12 (Briawan, 2014). Hasil penelitian Andasari (2017) menunjukkan bahwa ada hubungan signifikan antara asupan nutrisi dengan terjadinya anemia pada remaja puteri dengan Pvalue 0,038. Begitu pula hasil penelitian yang dilakukan oleh Hamidiyah (2018) menunjukkan bahwa semakin tinggi asupan nutrisi maka 3,01 kali semakin rendah pula santri terkena anemia.

Salah satu upaya yang dapat dilakukan dalam penanggulangan anemia adalah dengan suplementasi zat besi. Program suplementasi zat besi berupa konsumsi tablet tambah darah dilakukan setiap minggu di semua 
sekolah dengan peer group sharing dipantau langsung oleh guru. Dan monitoring setiap 3 bulan sekali oleh Puskesmas. Akan tetapi program ini belum berjalan maksimal dan supmenen tablet tambah darah yang diberikan perlu dievaluasi ulang mengingat merupakan produk kimia yang tentu kurang baik jika dikonsumsi secara rutin bagi ginjal.

Sehingga perlu dilakukan pengembangan produk sejenis berupa kapsul serbuk Moringan Oleifera Leaf substtitusi tablet tambah darah. Mengguakan serbuk Moringan Oleifera Leaf karena sayuran kelor semua bagian pohonnya dapat dimanfaatkan. Hasil penelitian While Gopalan, el al. (2010) menunjukkan bahwa seluruh bagian tanaman kelor bermanfaat bagi kesehatan. Begitu pula Bey (2010) menunjukkan kandungan Fe serbuk kelor 25 kali lipat lebih tinggi dibanding sayuran bayam, vitamin A 10 kali lipat lebih tinggi dibanding dengan wortel. Dan 7 kali lebih tinggi kandungan Vitamin $\mathrm{C}$ dibanding dengan jeruk. Sebagaimana yang diketahui $\mathrm{Fe}$ merupakan mineral yang sangat berpengaruh dalam pembentukan hemoglobin. Sedangkan vitamin A berperan dalam memobilisasi cadangan besi dalam tubuh untuk dapat mensintesis $\mathrm{Hb}$. Dan vitamin $\mathrm{C}$ berperan dalam meningkatkan abrsopsi zat besi.

Oleh karena itu, penting dilakukan penelitian pencegahan anemia remaja melalui perbandingan konsumsi suplementasi tablet tambah darah dan kapsul serbuk Moringan Oleifera Leaf di Pondok Pesantren Salafiyah Syafi'iyah Sukorejo.

Tujuan penelitian ini yaitu untuk mengetahui perbandingan konsumsi suplementasi tablet tambah darah dan kapsul serbuk Moringa Oleifera Leaf dalam pencegahan anemia remaja putri di Pondok Pesantren Salafiyah Syafiiyah Sukorejo.

\section{METODE PENELITIAN}

Penelitian ini merupakan penelitian kuantitatif dengan desain True Eksperimen. Lokasi penelitian dilakukan di Pondok Pesantren Salafiyah Syafi'iyah Sukorejo Situbondo dan laboratorium Politeknik Jember. Waktu penelitian dilakukan selama 10 bulan pada Tahun 2020. Populasi dalam penelitian ini adalah remaja putri di Pondok Pesantren Salafiyah Syafi'iyah Sukorejo Situbondo. Sampel dalam penelitian ini 
terdiri dari masing-masing 30 remaja putri baik kelompok intervensi maupun kontrol untuk uji pengaruh kadar hemoglobin menggunakan rumus :

$$
n=\frac{4 \bullet \sigma^{2} \bullet\left(z_{\alpha}+z_{\beta}\right)^{2}}{\left(\mu_{1}-\mu_{2}\right)^{2}}
$$

Pengambilan sampel menggunakan teknik simple random sampling . Kriteria inklusi sampel penelitian ini sebagai berikut:
a. Berusia 18-21 Tahun.
b. Telah mengalami menstruasi.
c. Sedang mengalami anemia saat penelitian.
d. Tidak memiliki gangguan tidur, dan tidur minimal 4 jam.
e. Tidak sedang menstruasi saat penelitian.

f. Tidak dalam keadaan puasa selama penelitian.

g. Bersedia menjadi responden penelitian.

Pengumpulan data dilakukan dengan uji perbedaan kadar Hb kepada 30 remaja putri yang anemia sebelum dan sesudah mengkonsumsi Kapsul serbul Moringa Oleifera Leaf dan 30 kelompok kontrol dengan mengkonsumsi tablet tambah darah.

Instrumen dalam penelitian ini yaitu 1) lembar observasi hasil pengamatan Kadar Hemoglobin, 3)
Lembar observasi recall gizi dan lama waktu tidur untuk mengontrol bias, 4) Set alat Hemoglobin Test merk Quick Check, darah responden, alcohol swab, blood lancet. Analisis data dilakukan menggunakan uji univariat dan bivariat (Wilcoxon).

\section{HASIL DAN PEMBAHASAN}

Distribusi Frekwensi Perbedaan Kadar Hb Sebelum dan Sesudah Konsumsi Tablet Tambah Darah dalam Pencegahan Anemia Remaja Putri di Pondok Pesantren Salafiyah Syafiiyah Sukorejo

Tabel 1 Distribusi Frekwensi Perbedaan Kadar $\mathrm{Hb}$ Sebelum dan Sesudah Konsumsi Tablet Tambah Darah dalam Pencegahan Anemia Remaja Putri

\begin{tabular}{|c|c|c|c|c|}
\hline No. & \multicolumn{2}{|c|}{ Keterangan } & $\mathbf{N}$ & $\%$ \\
\hline \multirow[t]{2}{*}{1} & Tidak & Ada & & \\
\hline & $\begin{array}{l}\text { Kenaikan } \\
\mathrm{Hb}\end{array}$ & Kadar & 19 & 63 \\
\hline \multirow[t]{3}{*}{2} & Ada & Kenaikan & 11 & 37 \\
\hline & Kadar $\mathrm{Hb}$ & & & \\
\hline & To & tal & 30 & 100 \\
\hline
\end{tabular}

Berdasarkan Tabel $\quad 1$ menunjukkan bahwa sebagian besar yaitu $63 \%$ tidak ada peningkatan kadar $\mathrm{Hb}$ pada responden sebelum dan sesudah konsumsi tablet tambah darah. 


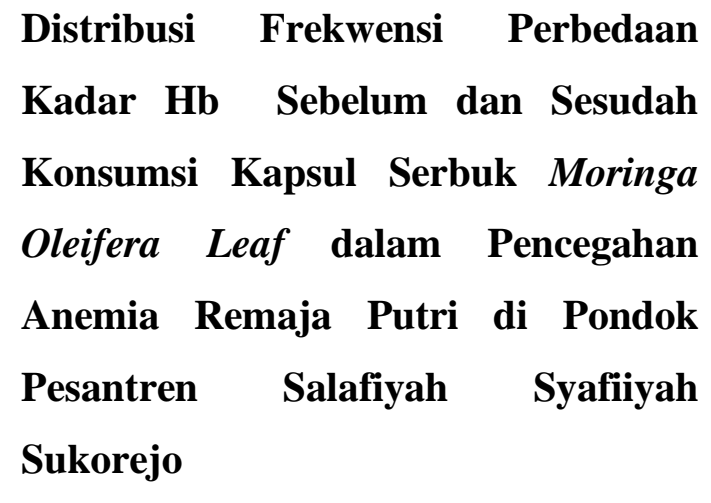

Tabel 2 Distribusi Frekwensi Perbedaan Kadar $\mathrm{Hb}$ Sebelum dan Sesudah Konsumsi Kapsul Serbuk Moringa Oleifera Leaf dalam Pencegahan Anemia Remaja Putri

\begin{tabular}{|c|c|c|c|c|}
\hline No. & \multicolumn{2}{|c|}{ Keterangan } & $\mathbf{N}$ & $\%$ \\
\hline \multirow[t]{2}{*}{1} & Tidak & Ada & & \\
\hline & $\begin{array}{l}\text { Kenaikan } \\
\mathrm{Hb}\end{array}$ & Kadar & 8 & 27 \\
\hline \multirow[t]{3}{*}{2} & Ada & Kenaikan & 27 & 73 \\
\hline & Kadar $\mathrm{Hb}$ & & & \\
\hline & To & tal & 30 & 100 \\
\hline
\end{tabular}

Berdasarkan Tabel 2 menunjukkan bahwa sebagian besar yaitu $73 \%$ ada kenaikan kadar $\mathrm{Hb}$ pada responden sebelum dan sesudah konsumsi kapsul serbuk Moringa Oleifera Leaf.

Perbedaan kadar Hb Sebelum dan Sesudah Konsumsi Tablet Tambah Darah dalam Pencegahan Anemia Remaja Putri di Pondok Pesantren Salafiyah Syafiiyah Sukorejo.

Hasil uji statistik menggunakan uji wilcoxon menujukkan hasil sebagaimana Tabel 3.
Tabel 3 Perbedaan kadar $\mathrm{Hb}$ Sebelum dan Sesudah Konsumsi Tablet Tambah Darah dalam Pencegahan Anemia Remaja Putri

\begin{tabular}{rr}
\hline $\mathrm{PostK1}$ - PreK1 \\
\hline $\mathrm{-}$ & $-1.201^{\mathrm{a}}$
\end{tabular}

Asymp. Sig. (2-tailed) .230

a. Based on positive ranks.

b. Wilcoxon Signed Ranks Test

\begin{tabular}{|c|c|}
\hline Berdasarkan & Tabel \\
\hline menunjukkan bahwa & tidak \\
\hline perbedaan kadar $\mathrm{Hb}$ & sebelum dan \\
\hline sesudah konsumsi tablet & tambah dara \\
\hline dengan Pvalue 0,23. & Hal ini juga \\
\hline ditunjukkan dengan mean & pre post kadar \\
\hline $\mathrm{Hb}$ pada responden & sebelum da \\
\hline $\begin{array}{l}\text { sesudah konsumsi tablet } \\
\text { sebesar }-0.3 \mathrm{gr} / \mathrm{dL}\end{array}$ & \\
\hline
\end{tabular}

Perbedaan kadar Hb Sebelum Dan Sesudah Konsumsi Kapsul Serbuk Moringa Oleifera Leaf dalam Pencegahan Anemia Remaja Putri di Pondok Pesantren Salafiyah Syafiiyah Sukorejo

Hasil uji statistik menggunakan uji wilcoxon menujukkan hasil sebagaimana Tabel.4. 
Tabel 4 Perbedaan kadar $\mathrm{Hb}$ Sebelum dan Sesudah Konsumsi Kapsul Serbuk Moringa Oleifera Leaf dalam Pencegahan Anemia Remaja Putri

\begin{tabular}{lc}
\hline & PostKa2 - PreKa1 \\
\hline $\mathrm{Z}$ & $-1.865^{\mathrm{a}}$
\end{tabular}

Asymp. Sig. (2-tailed) .062

a. Based on negative ranks.

b. Wilcoxon Signed Ranks Test

Berdasarkan Tabel 4 menunjukkan bahwa tidak ada perbedaan kadar $\mathrm{Hb}$ sebelum dan sesudah konsumsi Kapsul Serbuk Moringa Oleifera Leaf dengan Pvalue 0,062. Akan tetapi jika dilihat dari mean pre post kadar $\mathrm{Hb}$ pada responden sebelum dan sesudah konsumsi Kapsul Serbuk Moringa Oleifera Leaf menujukkan ada peningkatan kadar $\mathrm{Hb}$ sebesar $0,59 \mathrm{gr} / \mathrm{dL}$.

\section{Perbandingan}

\section{Konsumsi}

Suplementasi Tablet Tambah Darah dan Kapsul Serbuk Moringa Oleifera

Leaf dalam Pencegahan Anemia Remaja Putri di Pondok Pesantren Salafiyah Syafiiyah Sukorejo

Hasil uji statistik menggunakan uji mann whitney menujukkan hasil sebagaimana Tabel 5.
Tabel 5. Perbandingan Konsumsi Suplementasi Tablet Tambah Darah dan Kapsul Serbuk Moringa Oleifera Leaf dalam Pencegahan Anemia Remaja Putri

\begin{tabular}{lr}
\hline & \multicolumn{1}{c}{ Hasil } \\
\hline Mann-Whitney U & 316.000 \\
Wilcoxon W & 781.000 \\
Z & -1.985 \\
Asymp. Sig. (2-tailed) & .047 \\
\hline
\end{tabular}

a. Grouping Variable: group

Berdasarkan Tabel 5 menunjukkan bahwa ada perbedaan kadar $\mathrm{Hb}$ sebelum dan sesudah konsumsi Konsumsi Suplementasi Tablet Tambah Darah dan Kapsul Serbuk Moringa Oleifera Leaf dalam Pencegahan Anemia Remaja Putri di Pondok Pesantren Salafiyah Syafiiyah Sukorejo Anemia Remaja Putri di Pondok Pesantren Salafiyah Syafiiyah Sukorejo dengan Pvalue 0,047.

\section{SIMPULAN DAN SARAN}

Simpulan penelitian ini yaitu: 1) Tidak ada perbedaan kadar $\mathrm{Hb}$ sebelum dan sesudah konsumsi tablet tambah darah dalam pencegahan anemia remaja putri di Pondok Pesantren Salafiyah Syafiiyah Sukorejo ( Pvalue 0, 23) . 2) Tidak ada perbedaan kadar $\mathrm{Hb}$ sebeluum dan sesuai konsumsi kapsul serbuk Moringa Oleifera Leaf dalam 
pencegahan anemia remaja putri di Pondok Pesantren Salafiyah Syafiiyah Sukorejo (Pvalue 0,062). 3) Ada perbedaan konsumsi suplementasi tablet tambah darah dan kapsul serbuk Moringa Oleifera Leaf dalam pencegahan anemia remaja putri di Pondok Pesantren Salafiyah Syafiiyah Sukorejo (Pvalue 0,047).

Saran dalam penelitian ini yaitu: 1) Perlu dilakukan penelitian lanjutan dengan menambahkan waktu intervensi sesuai masa pembentukan hemoglobin yaitu selama intervensi 90 hari dengan mengontrol betul bias dalam penelitian agar uji beda perubahan $\mathrm{Hb}$ dapat dianalisis secara signifikan. 2)Perlu adanya perhatian khusus bagi para akademisi dan tenaga kesehatan setempat dalam memandang kelor sebagai sumber daya alternatif upaya preventif maupun kuratif.

\section{DAFTAR PUSTAKA}

Almatsier, S., 2009. Prinsip Dasar Ilmu Gizi. Jakarta: Gramedia.

Andasari, K., 2017. Hubungan Asupan Nutrisi dengan Anemia Santri Ma'had Aly. Situbondo: Akademi Kebidanan Ibrahimy.

Bey., 2010. All Things Moringa.

Bhagarva, A. \& et.al., 2001. Dietary Intakes and Socioeconomic Factors are Associated with The
Hemoglobin Concentration of Bangladesh Women. Am J Clin Nutr, Volume 131, pp. 758-764.

Briawan,D. et al , 2012. KKonsumsi Pangan, Bioavailabilitas Zat Besi dan Status Anemia Siswi di Kabupaten Bogor. Prosiding Seminar Hasil Penelitian IPB. pp.219-230

Dinas Kesehatan Kab.SItubondo, 2018. Profil Kesehatan Kabupaten Situbondo. Situbondo: Dinas Kesehatan Kab.Situbondo

Direktorat Gizi Masyarakat Kemenkes RI, 2016. Program Pencegahan \& Penanggulangan Anemia pada Rematri dan WUS. Jakarta: Kemenkes RI

Fuglie, L. J., 2001. The Miracle Tree: Moringa oleivera: Natural Nutrition for the Tropics. Training Manual. Church World Service. Dakar, Senegal

Gopalan, C, 2010. Nutrition Research in Southeast Asia. New Delhi, WHO

Hamidiyah, A., Rohmani, L. \& Zahro, N. A., 2018. Faktor Determinan Anemia Santri Putri. Oksitosin: Jurnal Ilmiah Kebidanan, 6(1), pp. 64-72.

Kustyaningsih, E., 2007. Perbedaan Tingkat konsumsi $\mathrm{Fe}$, vitamin $C$ dan kadar hemoglobin pada santri putridi pondok pesantren dengan dan tanpa pelayanan gizi institusi (Studi di pondok pesantren Modern Selamat dan pondok pesantren putri Bani Umar Al Karim Kabupaten 
Kendal. Semarang: Universitas Diponegoro.

Lynch, S., 2000. The Potential Impact of Iron Suplementation During. Am. J. Clin. Nutr, Volume 130, p. 488S.

Mazrizal, 2007. Anemia Defisiensi Besi. Jurnal Kesehatan Masyarakat FK Unand, 2(1).

Notoatmodjo, S., 2007. Promosi Kesehatan \& Ilmu Perilaku. Jakarta: Rineka Cipta.

Notoatmodjo, S., 2010. Metodologi Penelitian Kesehatan. jakarta: Rineka Cipta.

Notobroto, H. B. \& Chatarina, U., 2000. Determinan epidemiologi anemia pada remja putri di pondok pesantren di Surabaya. Surabaya: Lembaga Penelitian Universitas Airlangga.

Kementrian Kesehatan RI., 2018. Profil Kesehatan. Jakarta: Kemenkes RI.

Santoso, S., 2004. Dinamika Kelompok Sosial. Jakarta: Bumi Aksara.

Santrock, J. W., 2007. Adolescence. Perkembangan Remaja. 6 (alih bahasa :Shinto B, Adelar dan Sherly Saragih) ed. Jakarta: Erlangga.

Sanjur, D., 1982. Social and Cultural Prespectif in Nutrition. New York: Prentice Hall.

Sediaoetomo, A., 1992. Ilmu Gizi untuk Mahasiswa dan Profesi. I ed. Jakarta: Dian Rakyat.

Supariasa, 2002. Penilaian Status Gizi. Jakarta: EGC.Shah, B. \& Gupta, P., 2002. Anemia in
Adolencent Girls: A Preliminary Report from SemiUrban Nepal. Indian Pediatrics, Volume 39, pp. 1126-1130.

Soan, Y. A., 2018. Hubungan Status Gizi dan Aktivitas Fisik dengan Anemia Mahasiswa Kebidanan. Situbondo: Prodi D III Kebidanan Fakultas Ilmu Kesehatan Universitas Ibrahimy.

Sediaoetomo, A., 1992. Ilmu Gizi untuk Mahasiswa dan Profesi. I ed. Jakarta: Dian Rakyat

Sya`Bani, I. R. N. \& Sumarmi, S., 2016. Hubungan Status Gizi Dengan Kejadian Anemia Pada Santriwati Di Pondok Pesantren Darul Ulum Pterongan Jombang. Jurnal Keperawatan Muhammadiyah, 1(1), pp. 7-15.

Yip, R., 1998. The Challenge of Improving Iron Nutrition. European Journal of Clinical Nutrition.

Zarianis, 2006. Efek Suplementasi BesiVitamin $C$ dan Vitamin $C$ terhadap kadar Hemoglobin Anak Sekolah Dasar yang Anemia di Kecamatan Sayung Kabupaten Demak , Semarang: Universitas Diponegoro. 